\title{
PIERRE-JEAN LABARRIÈRE (1931-2018): UMA VIDA E O LEGADO FILOSÓFICO HEGELIANO *
}

Pierre-Jean Labarrière (1931-2018): His life and Hegelian philosophical legacy

\author{
Adilson Felicio Feiler ** \\ Agemir Bavaresco ***
}

Resumo: Relembrando o jesuíta intelectual Pierre-Jean Labarrière, reconstruímos sua trajetória biográfica e intelectual como expressão de gratidão e reconhecimento pela sua missão. Homem incansável e vigoroso, desde jovem Labarrière mostrou suas habilidades intelectuais. Muito atento às mudanças e desafios da história, não teve medo de enfrentar as provocações de pensadores como Hegel, de quem se tornou um grande estudioso. Labarrière aproveitou, inclusive, $o$ pensamento de Hegel, para dar respostas a inúmeros impasses com os quais o Cristianismo Católico francês se confrontava.

Palavras chave: Filosofia. Labarièrre. Hegel. História. Legado.

Abstract: This article aims to recall the Jesuit scholar Pierre-Jean Labarrière by reconstructing his biographical and intellectual path, as an expression of gratitude and recognition for his mission. As a young, tireless and vigorous man, Labarrière already showed his intellectual abilities. Very attentive to the changes and challenges of history, he was not afraid to respond to the provocations of

\footnotetext{
* Artigo recebido em 26/03/2020 e aprovado para publicação em 16/05/2020.

** Doutor em Filosofia. Professor do Programa de Pós-graduação em Filosofia da Universidade do Vale do Rio dos Sinos (UNISINOS).

*** Doutor em Filosofia. Professor do Programa de Pós-graduação em Filosofia da Pontifícia Universidade Católica do Rio Grande do Sul (PUCRS).
} 
thinkers, such as Hegel, of whom he became a great scholar. Labarrière even took advantage of Hegel's thinking to address the numerous impasses faced by French Catholic Christianity.

Keywords: Philosophy. Hegel. Labarrière. History. Legacy.

\section{Considerações Iniciais}

7 ranscorrido um ano do falecimento do filósofo jesuíta Pierre-Jean Labarrière, registramos nosso reconhecimento e homenagem pela sua trajetória intelectual. Trazemos, aqui, dados da biografia intelectual de Labarrière, entrelaçados com elementos que marcaram toda uma geração de pensadores, preocupados em compreender a realidade de seu tempo à luz do texto hegealiano. $\mathrm{O}$ esforço de Labarrière foi, inclusive, $\mathrm{o}$ de fazer com que o texto de Hegel fosse traduzido com toda a sua força nativa. Ou seja, que pela fidelidade à letra de Hegel, se tivessem condições de traçar um diagnóstico da cultura, de modo a poder expressar, com a máxima clareza, caminhos que apontem para além das aporias fixadas pelas contradições da história.

Tal como Hegel, Labarrière pensa na importância de analisar as ligações entre a história e o pensamento, de modo a se reconciliarem na inteireza de um todo, em torno da noção de plenitude, numa nova luz. Esta luz aponta para uma nova visão antropológica, fundada na ideia de uma inteligência que compreendesse o ser humano como liberdade radical; assentada no domínio de uma ação concreta. Ele se preocupava com aquela ação que vai se mediatizando nas instituições sociais, encontrando nelas o seu sentido e realização. Portanto, a concretização da abertura do ser humano ao mundo, em sua radicalidade, corresponderia à coerência do ser em seu sentido de unidade em si e para si. Aquele ser imediato que se medeia em diversas instituições sociais, resultando como autoreflexividade, capaz de realizar uma confrontação e diálogo entre o seu e o nosso tempo.

O legado de Labarrière é de um valor indiscutível. Foi ele quem recepcionou de forma original e fiel na França, as reflexões sistemáticas de Hegel, em A Fenomenologia do Espírito. Se, por um lado, Labarrière se mostra fiel ao texto hegeliano, esclarecendo-o, por outro lado, tem, no texto hegeliano, uma ferramenta crítica para compreender a realidade de seu tempo, fazendo o texto de Hegel não ser uma letra morta, mas viva e atuante nos interstícios da história.

O nosso texto é dividido em três capítulos. O primeiro, intitulado Labarrière e seus primeiros passos, se dedica a um relato dos primeiros anos de vida de Labarrière. Nele estão presentes não apenas dados corriqueiros 
da vida do Filósofo, mas também a forma como foi se preparando, desde a juventude, para o diálogo com Hegel, uma das grandes mentes que ajudaram a iluminar o seu pensamento. Na sequência aprofundamos a relação de Labarrière com o pensamento de Hegel através de um segundo capítulo denominado $O$ Estudioso de Hegel. Trata-se de perceber como o filósofo francês foi percebendo, no pensamento de Hegel, um alcance e uma genialidade sistêmica inigualável, até então. Concluímos com uma reflexão sobre como Labarrière concebe o legado hegeliano para se pensar o seu próprio tempo, mediante um terceiro capítulo intitulado Para além de Hegel. Ou seja, perceber quais as possibilidades de confronto e diálogo entre o tempo de Hegel e o de Labarrière. Através deste percurso, temos a intenção de contribuir com a manutenção do pensamento vivo de Labarrière, de modo a constatar que o movimento dialético do espírito descrito por ele continua a se realizar nos diferentes segmentos e instituições sociais.

\section{Trajetória de uma mente rica e polifacética}

O último dos onze irmãos, Pierre-Jean Labarrière nasceu em Norolles em Calvados em 21 de junho de 1931. Ele cresceu no castelo de Malou (que data do século $\mathrm{XV}$ ), na Normandia, onde morava sua família. Ele gostava de mostrar a fotografia deste castelo ao qual ele havia permanecido muito ligado. Sua mãe morreu em um acidente de carro em Viena, na Áustria, quando ele tinha 16 anos de idade. Pierre-Jean tinha ligações muito fortes com ela e nunca se recuperaria de seu desaparecimento. Era uma "dor de toda a vida".

Ele foi capaz de ler muito cedo. Também foi cedo que seu desejo de seguir a Cristo tomou forma. Aos seis anos já mostrava seu desejo de ser padre. Brilhante em seus estudos, talentoso tanto para a matemática quanto para a literatura, ingressou no noviciado da Companhia de Jesus aos 18 anos de idade em 1949. Concluída sua formação, foi ordenado sacerdote em 1963. Assim como Labarrière, a Companhia de Jesus na França legou-nos outras sumidades intelectuais, como Teilhard de Chardin. Estiveram também ligados a instituições dirigidas pela Companhia de Jesus vários nomes célebres como Descartes, Diderot e Voltaire. A França, com sua tradição intelectual, certamente influenciou Labarrière. Mesmo sendo considerada a filha primogênita do Cristianismo Católico, a França foi palco de inúmeros eventos conflituosos em relação à Igreja, que marcaram a história, como a Revolução Francesa. Portanto, a riqueza e diversidade de acontecimentos em solo francês será uma marca indelével na formação de Labarrière.

Ele também possui duas teses em filosofia: uma na Universidade Gregoriana de Roma, a outra em Paris-Nanterre sob a direção de Paul Ricoeur 
em 1980, publicada sob o título O Discurso da Alteridade: a lógica do experimento (PUF, 1983). Labarrière lecionou no Centro Sèvres, a Universidade jesuíta de Paris, e no Institut Catholique, também na capital francesa. Como jovem jesuíta, não temia confrontar-se com Hegel que, aos seus olhos, tinha tanta influência no pensamento moderno e com cuja filosofia um intelectual católico não podia deixar de se confrontar. Assim, ele ajudou muitos estudantes a se abrirem para essa obra, por sua Introdução à leitura da Fenomenologia do Espírito (Aubier, 1992). Esta introdução tem seu início em sua tese de Doutorado, defendida na Pontífícia Universidade Gregoriana, em Roma, em 1967, orientada por Pierre Henrici, tese intitulada Structures et mouvement Dialectique dans La phénomenologie de l'esprit de Hegel, (Estruturas e movimento dialético na Fenomenologia do Espírito de Hegel). Esta obra é considerada uma excelente introdução à compreensão da Fenomenologia do Espírito de Hegel

Além de ser um homem extraordinariamente talentoso em muitos aspectos, um esportista vigoroso, um músico talentoso, um cinéfilo exigente, ele foi um poeta que publicou várias coleções de poesia, incluindo Odes à noite de 1984, marcadas por sua inteligência exigente e rigorosa. Uma outra prova dessa capacidade de Labarrière é um texto intitulado Poiéticas: Quando a utopia se torna história, uma obra que mostra a influência da estética literária na filosofia contemporânea, relacionando mística, poesia e filosofia. Labarrière diz, neste texto: “(...) eu coloco estas lições sobre o tríplice sinal do Mestre Eckardt a mística, de Dante a poesia e de Hegel a filosofia." ${ }^{1}$ Com isso, vemos que ele se destacou em diversas áreas, além da filosofia. Suas capacidades fizeram dele uma mente aberta e plurifacética, sempre disposta a enfrentar desafios novos. Aliás, uma mente como a de Labarrière não permite fixar-se em um determinado ponto da história, mas é sensível às mudanças pelas quais vivemos no decorrer da história, apontando caminhos que repercutam em respostas aos diferentes desafios. Não que estas respostas tenham a intenção de serem prontas e acabadas, mas que, com ousadia e ímpeto, se permitam abrir horizontes com utopias. Utopias estas que, longe de se configurarem de maneira aleatória, seguem a metodologia hegeliana, uma: "(...) tradição utópica que se enriquece com aspectos complementares que põe em marcha uma lógica didática." ${ }^{2}$ Mediante esta lógica, se exercita a memória, derivada de representações fixas: esclarece-se a escrita e a resposta do pensamento político dentro do contexto de um poema. Com isso, mais uma vez, se mostra a capacidade de integração de Labarrière em áreas distintas em torno a problemáticas gerais que movem o pensamento.

\footnotetext{
${ }^{1}$ LABARRIÈRE, Pierre-Jean. Pö̈étiques. Quand l'utopie se fait histoire. Paris: Presses Universitaires de France, 1998, p. 5.

${ }^{2}$ LABARRIÈRE, Pierre-Jean. L'Utopie Logique. Paris: L'Harmattan, 1992, p. 4.
} 
Contudo, ainda temos outra área digna de nota que não poderia faltar em nossas considerações, a mística teológica e espiritual. Labarrière dedicou grande parte de sua carreira intelectual à pesquisa sobre o pensamento de Merstre Eckhart, um grande pensador místico do século XIV, representante da escola dominicana. Mestre Eckhart tem a intenção de estabelecer uma grande mística. No entanto, sem os devidos esclarecimentos com relação aos detalhes históricos, biográficos e teológicos, que perpassam a sua vida e atuação, a compreensão de sua obra, torna-se um empreendimento impossível. É esta a grande contribuição de Labarrière, graças aos longos anos de estudo e aprofundamento e tradução da obra de Eckhart. Este trabalho de Labarrière levou a "(...) compreender a estrutura de sua linguagem e de sua visão de mundo, ele esclarece o sentido das noções-chefe de divindade e faísca da alma" ${ }^{3}$ de Eckhart. Mediante as reflexões, fruto destes longos e frutuosos estudos em torno a este Mestre, Labarrière traça uma unidade primordial que perpassa tanto a noção do nascimento do ser humano em Deus como do nascimento de Deus no ser humano. Com isso, se evoca um tema fundamental a ser explorado em Hegel: o da unidade primordial ampla e sistemática, tema que marca a reflexão hegeliana de maneira decisiva e sobre o qual Labarrière foi-se afirmando como autoridade inconteste. A busca dessa unidade foi também o móvel de sua existência.

\section{O estudioso de Hegel}

Labarrière foi um dos melhores especialistas franceses de Hegel, porque, discípulo dos jesuítas hegelianos do escolasticado de Chantilly nos anos 50, tornou-se um notável tradutor com a apreciada colaboração de Gwendoline Jarcyk, um intérprete original de um pensamento difícil. Na sua obra sobre a Fenomenologia do Espírito ele esclarece que a história do pensamento é toda ela uma particularidade plena que se apresenta com uma luz nova. Disto se depreende uma compreensão do ser humano como liberdade radical. Labarrière, com muita clareza e precisão, mostra que o método em Hegel é uma marca fundamental de seu pensamento “(...) é o 'caminho' concreto, com suas etapas, com seu movimento, com seu ritmo, graças ao qual o espírito determina seu objeto e se assimila o seu conteúdo." ${ }^{4} \mathrm{E}$ mais adiante Labarrière diz ainda que "Sem este movimento dialético único que anima a pluralidade de suas estruturas, a Fenomenologia só seria uma construção fluida, sem ligação com a experiência em que se manifesta a

\footnotetext{
${ }^{3}$ LABARRIÈRE, Pierre-Jean; JARCZYK, Gwendoline. Maître Eckhart ou I'empreinte du désert. Paris: Albin Michel, 1995, p. 95.

${ }^{4}$ LABARRIÈRE, Pierre-Jean. Structures et mouvement dialectique dans La Phénoménologie de l'esprit de Hegel. Paris : Aubier, 1968, p. 31.
} 
inteligibilidade. ${ }^{5}$ Portanto, o movimento é um aspecto fundamental da Fenomenologia, tal como acentuou Labarrière; o movimento que caracteriza as estruturas do existir, e do qual deriva o reconhecimento. Theresa Calvet de Magalhães, recorda que: "Pierre-Jean Labarrière (1931-) procurava retornar a uma leitura do texto original, atenta às estruturas da obra e ao movimento que as anima, e portanto à função determinante que realiza aqui, por trás da consciência, a lógica." Magalhães reconhece, portanto, todo o esforço de Labarrière em acentuar o elemento hegeliano do movimento da Fenomenologia. O movimento é, pois, garantia da cientificidade de todo o projeto hegeliano. Neste sentido, a obra não pode ser lida como apenas uma introdução ao sistema da ciência, mas como apresentação do saber que aparece. Para “(...) Labarrière, a Fenomenologia do Espírito só pode ser considerada como "primeira parte do sistema" porque ela realiza a totalidade desse mesmo sistema; o conteúdo total do sistema é exigido para que possa se operar a conversão plena da consciência à verdade de sua própria certeza." Desse modo, a Fenomenologia é uma obra científica, e, nesta cientificidade, Hegel reúne os opostos em torno à ideia de sistema. "Labarrière insiste que essa unificação dos extremos, que são por um lado a história e, por outro lado, a religião, é tarefa de liberdade. Hegel não pode ser considerado como um "visionário que pronunciaria de uma vez por todas uma unidade posta e acabada"; ele propõe uma tarefa: 'o caráter "absoluto'. ${ }^{8}$ " Portanto, a unificação toma o caráter de processo, que vai-se realizando, um movimento contínuo que implica uma relação de agentes em prol da alteridade, dois indivíduos que se reconhecem mutuamente. "Labarrière propõe (...) que o "reconhecimento" só é pleno entre os dois indivíduos "quando cada um recebe do outro a relação que ele entretém consigo mesmo'. ${ }^{\prime \prime}$ Na base deste reconhecimento mútuo é que nasce a alteridade, fundamental para pôr em movimento o sistema de Hegel.

Pierre-Jean não se contentou, porém, com comentar e traduzir Hegel. Ele mesmo concebeu uma obra notável, como Deus hoje, progresso racional, decisão de liberdade (Desclée 1977), Unidade plural: louvor (Aubier, 1992) ou Acredite e Entenda: Abordagem Fenomenológica da Experiência Cristã (Cerf, 1999). Preocupado com a realidade na qual ele vivia, Labarrière se viu impulsionado a desenvolver um trabalho em torno ao problema das diferenças entendidas em sua unidade integral. Ou seja, o problema do mesmo e do outro - como se resolve essa dicotomia que parece ter querido se instalar na maneira como se entende o real. Labarrière quer entender a modernidade a partir de um esclarecimento filosófico, portanto, como ele

\footnotetext{
${ }^{5}$ Ibid., p. 44-45.

${ }^{6}$ MAGALHÃES, Theresa Calvet de. O reconhecimento em Hegel : leituras de Labarriére. In : Revista do Instituto de Hermenêtica Jurídica, n. 7, Belo Horizonte, setembro de 2009, p. 4.

${ }^{7}$ Ibid., p. 8.

${ }^{8}$ Ibid., p. 13.

${ }^{9}$ Ibid., p. 21.
} 
diz: “(...) uma aproximação nova de sua função estruturante ao benefício das práticas históricas da ciência, da política, da teologia e da arte (...) esta lógica fundamental propõe uma experiência que articula a origem das dimensões conexas do exterior e do interior. ${ }^{10 \prime}$ Ele pretende pensar a história mediante uma relação que se estabelece entre o discurso e a alteridade.

In memoriam ao testamento intelectual do filósofo Labarrière registramos sua tradução da Ciência da Lógica de Hegel que consumiu boa parte do seu tempo de pesquisador através de apresentação, notas e docência sobre esta obra, considerada por ele o centro pulsante de todo o sistema e pensamento hegeliano. Ele tinha como característica pesquisar e oferecer cursos em docência compartilhada com a filósofa Gwendoline Jarczyk. Uma marca intelectual a ser destacada é a parceria intelectual entre os dois filósofos que se caracterizou por fazer traduções de excelência das principais obras de Hegel. Queremos reconstituir, brevemente, a apresentação elaborada para cada um dos livros traduzidos da Ciência da Lógica de Hegel para explicitar a sua leitura lógica da obra hegeliana.

$\left.1^{\circ}\right)$ Apresentação ao livro O Ser (1972): Na história a lógica foi entendida apenas como um conjunto de regras formais que eram usadas para apreender a coisa na sua verdade, enquanto que a ontologia ou a metafísica expunham o conteúdo das categorias do ser (origem, natureza e essência). Esse modo de operar da lógica foi até o século 18, alcançando com o transcendentalismo kantiano o auge da separação entre forma e conteúdo, sujeito e objeto. A lógica hegeliana focar-se-á no método para unir aquelas categorias pelo auto-movimento das mesmas. Trata-se da correlação entre interior e exterior, ser e pensar. O ponto de partida da lógica é a imediatidade simples alcançada no fim do périplo da fenomenologia, isto é, a identidade do negativo e do positivo como identidade constitutiva de tudo o que é. O desenvolvimento da lógica e do sistema no ser puro é um movimento que leva em conta o duplo elemento: sujeito/ objeto, interior/exterior, forma/conteúdo. ${ }^{11}$

2º) Apresentação ao livro A doutrina da Essência (1976): A lógica tem uma estrutura binária em oposição/relação entre objetividade (Ser e Essência) e subjetividade (Conceito) e, ao mesmo tempo, uma relação ternária: Ser, Essência e Conceito. Esse movimento não é algo quantitativo como dizem os autores: "A exterioridade do ser, tendo-se refontalizado na interioridade da essência aparece como exterioriedade realizada em sua imanência. Do positivo ao positivo pelo negativo; do imediato à imediatidade pela mediação; do exterior ao exterior pelo interior: cada vez, é o termo primeiro

${ }^{10}$ LABARRIÈRE, Pierre-Jean. Le discours de l'altérité. Une logique de l'expérience. Paris: Presses Universitaires de France, 1983, p. 6.

${ }^{11}$ LABARRIÈRE, Pierre-Jean. Science de la logique. L'Être. Traduction, presentation, notes par P.-J. Labarrière et Gwendoline Jarczyk, Paris: Aubier, 1972, p. 13-25. 
e o último que manifesta sua própria riqueza constitutiva de si mesmo" (Id., p. 13). As estruturas referenciais da realidade ou do pensamento dialético é o movimento da reflexão em seus três tempos: reflexão ponente, exterior e determinante. Os autores aplicam estas três estruturas a toda lógica, ao que se opõe, por exemplo, o filósofo italiano Vincenzo Vitiello, delimitando-as à esfera da Essência e até o fim da $1^{\text {a }}$ seção do Conceito. Porém, os autores, entendem a imanência do movimento da reflexão nas determinações do Ser como uma relação entre interior e exterior e a Essência aparece como uma interioridade refletida do Ser, sendo a Essência a explicitação das determinações de reflexão. Eles defendem a tese de que a reflexão é o movimento fundador e as suas determinações constituem a estrutura referencial que permite desenvolver e interpretar todo o conteúdo do Ser, da Essência e do Conceito. ${ }^{12}$

$3^{\circ}$ ) Apresentação ao livro A doutrina do Conceito (1981): Os autores expõem as diversas esquematizações do movimento, criticando quase um dos únicos esquemas, o ternário, que foi mantido para expressar a significação do processo dialético. Eles acrescentam o binário que explicita a relação reflexiva do real consigo mesmo e a quadruplicidade que mostra a força contraditória do termo mediador. O sistema aberto flui de sua auto-exposição como uma totalidade em movimento reflexivo. Não se trata de um monismo que elimina a alteridade ou se reduz a uma reduplicação de espelhamento do mesmo como é o caso da substância spinozista ou da mônada leibniziana, mas trata-se de uma unidade que emerge do jogo 'especulativo' da dualidade do conteúdo e forma, interior e exterior, sujeito e objeto, liberdade e necessidade, conceito e história, lógica e ciências reais que rompe com o dualismo ou o monismo. ${ }^{13}$

O caráter contraditório do esquema binário implica a dupla pressuposição da estrutura reflexiva que se explicita no movimento ternário dos três termos, em que o primeiro e o terceiro termo desse processo são idênticos, porém, o movimento que leva de um ao outro é realizado pela mediação negativa e seu funcionamento é a unidade dos termos em relação dual. A triplicidade de termos precisa ser compreendida em seu momento de mediação como uma dupla forma negativa, que expressa o processo de exterioridade, ao mesmo tempo, como o resultado do processo de exteriorização e o ponto de partida de interiorização mediatizante. Trata-se de um processo a quatro termos que articula os momentos da primeira imediatidade $\left(\mathrm{I}^{1}\right)$, com o mediatizado/negação positiva $\left(\mathrm{M}^{1}\right)$, e o mediatizante/negação negativa $\left(\mathrm{M}^{2}\right)$, e enfim com o que se torna um novo imediato $\left(\mathrm{I}^{2}\right)$. $\mathrm{O}$ esquema binário

\footnotetext{
${ }^{12}$ LABARRIÈRE, Pierre-Jean. Science de la logique. La doctrine de l'essence. Traduction, presentation, notes par P.-J. Labarrière et Gwendoline Jarczyk, Paris: Aubier, 1976, p. 21.

${ }^{13}$ LABARRIÈRE, Pierre-Jean. Science de la logique. La logique subjective ou doctrine du concept. Traduction, presentation, notes par P.-J. Labarrière et Gwendoline Jarczyk, Paris: Aubier, 1981, p. 13.
} 
junta-se ao ternário num processo quádruplo que expressa o infinito da negação, isto é, a inesgotável refontalização do movimento da unidade do real levando em conta o outro como outro (Id. p. 14).

A unidade da quadruplicidade expressa uma filosofia do imediato, isto é, o $1^{\mathrm{o}}$ momento $\left(\mathrm{I}^{1}\right)$ é o da posição de onde emerge o esquema binário ou da diferença da unidade ou da identidade; o $2^{\mathrm{o}}$ momento afirma a exterioridade reflexiva através do mediatizado $\left(\mathrm{M}^{1}\right)$ e mediatizante $\left(\mathrm{M}^{2}\right)$; enfim o $3^{\text {o }}$ momento é a determinação como retorno do ser posto no termo ponente, isto é, uma nova imediatidade $\left(\mathrm{I}^{2}\right)$ na figura da verdade que se tornou verificada. A leitura da lógica focada no imediato como unidade fundamental explicita-se no jogo da "aparência" (Schein) do Ser $\left(\mathrm{I}^{1}\right)$ que se aprofunda na Essência $\left(\mathrm{M}^{1}\right)$ como reflexividade da diferença $\left(\mathrm{M}^{2}\right)$ até alcançar a efetividade enquanto imediatidade verificada $\left(\mathrm{I}^{2}\right)$. A aparência é o termo técnico que permite dizer o imediato na totalidade em movimento (Id. p. 15-16).

A segunda seção da Doutrina do Conceito apresenta um esquema estrutural que coloca em relação de paralelismo os diferentes momentos do imediato: O ser aí na economia do Ser $\left(\mathrm{I}^{\mathrm{S}}\right)$; a existência, depois a efetividade e a substancialidade na Essência $\left(\mathrm{I}^{\mathrm{E}}\right)$; e a objetividade no processo do Conceito $\left(\mathrm{I}^{\mathrm{C}}\right)$.

No Conceito trata-se fundamentalmente do sujeito como sujeito livre enquanto unidade do esquema binário: subjetividade-objetividade. No interior da primeira seção do Conceito, a subjetividade apresenta a dualidade do juízo que se resolve no esquema ternário do silogismo. Esse processo é o movimento do conceito do abstrato ao concreto como determinação da totalidade indeterminada na objetividade. Então, o processo a quatro tempos, na mediação mediatizante da objetividade mecânica e química no conceito teleológico que conduz ao imediato da ideia (Id. p. 16-17).

A lógica objetiva começa com o périplo da imediatidade do Ser que se diferencia em seu interior e aparece como Essência. O momento específico da mediação é a essência como reflexão mediatizada do ser e o mediatizante da existência que se expressa no processo a quatro tempos: a imediatidade do ser $\left(\mathrm{I}^{1}\right)$, o mediatizado da essência como aparência $\left(\mathrm{M}^{1}\right)$, o mediatizante como fundamento $\left(\mathrm{M}^{2}\right)$, e a imediatidade que se tornou existência como 'ser essêncial' $\left(\mathrm{I}^{2}\right)$ (Id. p. 18). Objeto e sujeito são duas faces da mesma realidade binária que se articula em ternária e amplia em quaternária: "Ser, essência como reflexão, substância, conceito - completam o retorno da dualidade sujeito-objeto na unidade do real sob a razão de sua imediatidade" (Id. p. 19).

A lógica no sistema se articula igualmente segundo as esquematizações binária, ternária e quaternária. Uma leitura reflexiva do real como totalidade é feita a partir dos três silogismos do ser aí, da reflexão e da necessidade. O silogismo da necessidade coloca a lógica como meio termo da natureza 
e do espírito. A lógica é a unidade do sistema em seus quatro momentos: a natureza $\left(\mathrm{I}^{1}\right)$, a lógica como lógica subjetiva $\left(\mathrm{M}^{1}\right)$, a lógica como lógica objetiva $\left(\mathrm{M}^{2}\right)$, enfim o espírito $\left(\mathrm{I}^{2}\right)$. "Há uma exata correspondência entre esse esquema e aquele que estrutura a Ciência da Lógica: Ser/Natureza, Essência como reflexão/Lógica subjetiva, Substância/Lógica objetiva, Espírito/Conceito" (Id. p. 21). Os autores concluem essa apresentação com este parágrafo sintetizador de sua leitura da lógica hegeliana:

“No silogismo hegeliano, o conteúdo, que é o mediatizante, está do lado do meio termo, enquanto que os extremos constituem a exterioridade de sua expressão 'formal'. Como meio termo, o conteúdo é necessariamente ao mesmo tempo sujeito e objeto; a distinção lógica entre mediatizado e mediatizante cai no interior do mediatizante. E, portanto, significativo dizer que é no extremo de sua exterioridade - como substância, como lógica objetiva - que o sujeito, potência reflexiva, pode 'se lembrar' dele mesmo. O sujeito é dito como 'mediatizado' enquanto ele se mediatiza na objetividade onde ele aparece como 'mediatizante'. Há uma primazia lógica do sujeito, que detém a primazia lógica do conceito; mas sua efetividade emerge no poder que é dele dizer-se até na exterioridade objetiva" (Hegel, Apresentação, 1981, p. 21).

Reconstituímos as três apresentações da Ciência da Lógica em que Labarrière, juntamente com Jarczyk, sintetiza, pode-se dizer, a sua leitura global da filosofia hegeliana. Aqui, estão explicitadas as linhas mestras de sua compreensão do sistema hegeliano em geral e de sua lógica em particular. Com essa reconstrução rendemos nossa homenagem de gratidão e reconhecimento a Pierre Jean Labarrière, recordando saudosos os seus Seminários aos quais tivemos a oportunidade de assistir no Centre Sèvres de Paris ${ }^{14}$.

\section{Para além de Hegel}

Longe de se limitar a Hegel, seu gosto pela espiritualidade levou Labarriére ao misticismo renano (por exemplo, Mestre Eckhart ou a gravura do deserto, Albin Michel, 1995 ou suas traduções do mesmo) e a João da Cruz, ao qual ele dedicou vários seminários ou cursos. Tendo se dedicado ao estudo de Hegel e da mística medieval, ele contribuiu ativamente para a redescoberta do Mestre Eckhart e para a promoção do pensamento de João da Cruz e Teresa d'Ávila. Assim se mostra, mais uma vez, a natureza de Labarrière, profundamente preocupado em estabelecer pontes entre várias instâncias do pensamento. No caso concreto, Labarrière enceta a relação entre o pensamento filosófico e a mística cristã. Esta dimensão de aproximar

\footnotetext{
${ }^{14}$ Agemir Bavaresco participou dos Seminários ministrados, normalmente, em docência compartilhada por P.-J. Labarrière e G. Jarczyk entre os anos 1995-1997.
} 
extremos, tal como já acompanhamos em análises anteriores, é uma das marcas do pensamento de Hegel, e que foi captado muito bem por Labarrière. Como aproximar o absoluto do pensamento e a contingência da história, eis, em resumo, o grande desafio que abre o pensamento de Hegel. Não que o filósofo alemão tenha alcançado a resposta, mas que lança para nós o desafio de seguir apostando na empreitada. "A história intermediária, não raro de maneira dura, e sem que isto se possa imputar ao livre iniciador que ele foi, nos advertiu sobre o insucesso global da tentativa por ele feita de reconciliar razão e efetividade o absoluto de um pensamento livre e a contingência da história. Fica-nos a tarefa de pensar por nós mesmos, com novos recursos. ${ }^{15 "}$ Característica própria do pensamento filosófico é, na sequência de críticas e de aceitações, levar o pensamento ao seu auge de maturidade, a fim de responder aos desafios que marcam o tempo vivido.

Labarrière, como tantos outros leitores e estudiosos de Hegel, se pergunta: Hegel chegou a efetivar os propósitos a que se propunha? E Labarrière afirma: "Hegel 150 anos depois: seguindo o seu exemplo, a melhor maneira, talvez, de encontrarmos a nós mesmos será refletir sobre as falhas que arrastaram esse pensamento a um insucesso, ao menos relativo, esperando que outros, depois de nós, encontrem lazer para tematizar ${ }^{16}$." Eis a sina de tantos pensadores em apontar pistas para responder aos desafios que marcam a atualidade do pensamento, mas não vivenciar as respostas como determinativas, que deste mesmo pensamento se vai colhendo. Por essa razão, estudiosos de Hegel, como Labarrière, ajudam a pensar para além de Hegel, a fim de não permanecer no dedo que aponta o horizonte, e sim fitar o horizonte. Foi este horizonte do conhecimento o motivo fundamental no qual Hegel se empenhou.

Quando se fala em horizonte, se está apontando para algo que está para além, portanto, algo dinâmico, algo que extrapola os limites que se impõe ao pensamento. É este, segundo Labarrière o papel da dialética: um movimento que não se fixa em momentos estáticos, mas que reflete a dinamicidade de momentos de passagem, momentos que perfazem uma transitividade do real. Neste sentido, como recorda Marcos Fábio Alexandre Nicolau, “(...) a estrutura do processo dialético hegeliano, dita por muitos manuais 'triádica', poderia ser tida, com aval do próprio Hegel, como constituída por quatro fases. ${ }^{17 "} \mathrm{O}$ mais importante, no que tange ao movimento dialético é concebê-lo como movimento, como a dinamicidade do real, para além do engessamento fixista.

\footnotetext{
${ }^{15}$ LABARRIÈRE, Pierre-Jean. Science de la logique. La logique subjective ou doctrine du concept. Traduction, presentation, notes par P.-J. Labarrière et Gwendoline Jarczyk, Paris: Aubier, 1981, p. 178.

${ }^{16}$ Ibidem.

${ }^{17}$ NICOLAU, Marcos Fábio Alexandre. Método e ato filosófico em Hegel. In: Revista Dialectus, ano 01, n. 02 janeiro-junho 2013, p. 9.
} 
Tal como a dialética também a lógica é um outro componente fundamental hegeliano que Labarrière trabalha de maneira particular. A lógica atua como princípio organizador, por trás da consciência, na relação senhor e escravo, o que Labarrière constata de forma especial na Fenomenologia do Espírito. André Oliveira Costa constata que este mesmo princípio da lógica hegeliana que Labarrière aplica à Fenomenologia do Espírito, também pode ser aplicado à Ciência da Lógica.

A interpretação de Labarrière sobre a figura do senhor e do servo se sustenta na relação que se estabelece entre a Fenomenologia do Espírito com o Sistema filosófico de Hegel, particularmente com a Ciência da Lógica. Para o primeiro, é possível verificar uma "lógica por trás da consciência", na medida em que essas duas obras não podem ser consideradas independentemente, mas apenas uma em relação à outra. Isso permite que se identifique, por exemplo, na figura do senhor e do servo, os mesmos princípios organizadores de determinado momento da Ciência da Lógica. ${ }^{18}$

A lógica por trás da consciência, tal como trabalhada por Labarrière, é, na visão de Costa, a mesma lógica que Hegel trabalha na Doutrina da Essência na Ciência da Lógica. Segundo Costa, o Ser se volta sobre si mesmo e se encontra, ao mesmo tempo, vinculado com o ser imediato que the é extrínseco. Portanto, uma duplicação entre ser intrínseco e extrínseco, que põe, na unidade, a diferença. Ou seja, consiste na unidade entre interioridade essencial da consciência com a exterioridade do ser imediato, tal como está na Doutrina da Essência, assim como na autoconsciência da unidade da determinação universal entre o senhor e o escravo.

A unidade que evoca diferença traz também a noção de alteridade que Labarrière evoca na dimensão do si mesmo como um outro. A noção de reconhecimento, segundo Theresa Calvet Magalhães ${ }^{19}$, que Labarrière trabalha sobre a Fenomenologia do Espirito evoca a alteridade. Consiste num outro que é reconhecido como outro, porém não sem a dimensão de unidade num todo sistemático.

Em uma entrevista concedida a Revista IHU da Unisinos, Labarrière salienta que a Fenomenologia do Espirito é uma obra fundamental para entender diversos processos de transformações pelos quais passa a civilização. No entanto, é inverídico o fato de se pretender explicar todos os fatos unicamente a partir de Hegel. O filósofo alemão não possui respostas para todos os problemas, nem tampouco, soluções prontas para todos os impasses. Labarrière sente a necessidade de clarificar que Hegel foi,

\footnotetext{
${ }^{18}$ COSTA, André Oliveira; BAVARESCO, Agemir. Movimento lógico da figura hegeliana do senhor e do servo. In: Trans/Form/Ação, Marília, v. 36, n. 1, p. 37-60, Jan./Abril, 2013, p. 39.

${ }_{19}$ MAGALHÃES, Theresa Calvet. Imputabilidade, responsabilidade, reconhecimento: uma releitura do percurso realizado em soi-même comme un autre. In: Sapere Aude - Belo Hori-

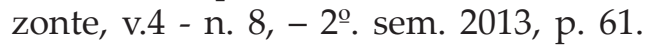


muitas vezes, mal interpretado, tal como, em grande medida, foi feito por Kojève e por Marx.

Pretendíamos reagir diante de uma leitura redutora tão amplamente aceita na Universidade francesa, que fazia de Hegel o defensor de um intelectualismo marcado, em especial, por duas teses inspiradas justamente por Kojève: a pretensão final de um "saber absoluto" entendido como um "fim da história" que anularia qualquer referência à contingência, e uma profissão de ateísmo que, a Marx, só lhe restaria selá-la de modo definitivo (este último ponto resultando de uma má interpretação da relação religião / filosofia entendida como uma Aufhebung, da qual só se considerava então o aspecto de abolição). ${ }^{20}$

Labarrière lutou para se realizar uma leitura o mais original, e o menos possível partidária de Hegel. Somente uma leitura desse molde seria capaz de afastar os diversos mal-entendidos que rondam a interpretação de Hegel. E, como Labarrière, bem notou, diversas leituras mais atrapalharam que ajudaram para uma compreensão mais isenta de preconceitos.

O conjunto da obra de Pierre-Jean Labarrière atesta o enfrentamento de preconceitos. Os seus escritos e a irradiação de seus ensinamentos nas Faculdades Jesuítas de Paris (Centro Sèvres), no Instituto Católico de Paris, bem como a sua participação, por muitos anos, do trabalho do Colégio Internacional de Filosofia, o que o levou a participar em muitas conferências no exterior, constitui um legado de inigualável envergadura.

Homem constantemente insinuante, Pierre-Jean continuará sendo uma grande testemunha dessa ousadia de pensamento sem a qual a fé cristã vai-se enfraquecendo em práticas rituais ou em retiros cautelosos. Aos 12 de julho de 2018 Labarrière vem a falacer, deixando um legado de riqueza inestimável.

\section{Considerações Finais}

Ao realizarmos este pequeno sobrevoo sobre um pouco da obra de Labarrière, constatamos a genialidade de alguém que ousou romper paradigmas a fim de responder a diversos questionamentos próprios de seu tempo. Contudo, o fato de romper paradigmas não implica em afastar-se do pensamento que se depreende da letra original de um determinado autor em questão, no caso concreto de Hegel. Pelo contrário, o filósofo francês enceta um caminho que o conduz aos aspectos que correspondem

${ }^{20}$ LABARRIÈRE, Pierre-Jean. Fenomenologia do Espírito uma introdução à 'modernidade'. Entrevista realizada pela Revista do Instituto Humanitas (IHU), São Leopoldo, 30 de abril de 2007, Edição 217, p. 21-22. 
à tessitura original do pensamento hegeliano. Mediante este excurso, Labarrière conseguiu tornar o pensamento de Hegel não apenas válido em sua versão mais original, mas legível ainda hoje, e capaz de responder aos impasses próprios da época em questão.

Como religioso jesuíta, ele teve que sofrer inúmeros revezes, próprios dos que, voluntariamente, se dispõem a submeter-se à direção de uma instituição. Esta submissão não diz respeito apenas a abrir mão de uma administração econômica, mas acima de tudo, de pensamento. E isso se torna tanto mais forte em se tratando de lidar com a pesquisa científica. Lidar com o pensamento de filósofos como Hegel, dentro de uma conjuntura marcada pelo peso moral institucional, acarreta dúvidas e impasses, e inclusive, pode conduzir ao desânimo e ao fracasso da carreira acadêmica. Um exemplo bem próximo a Labarrière é o de um outro pensador: Teilhard de Chardin. Ambos são próximos seja por pertencerem a uma mesma instituição religiosa, seja por terem sido pensadores de grande envergadura. Ambos, cada um ao seu modo, sofreram o peso dos limites próprios de quem assume submeter-se a uma instituição, sem por isso perderem o apreço mútuo ou renunciarem à sua produção e criatividade, justamente porque sabiam que a ela deviam em primeiro lugar sua força e inspiração. Mas, o que chama a atenção na vida de Labarrière é o drama de alguém que teve seus longos últimos anos mergulhados no silêncio, forçado pela enfermidade, acometido de uma doença degenerativa, isolado do público, para o qual devotou todos os esforços de sua vida.

Como estudioso de Hegel, o filósofo francês trouxe a público um conhecimento fundamental, principalmente no que tange ao esclarecimento sobre a Fenomenologia do Espírito. Desde a sua tese doutoral, Labarrière devotou-se a esclarecer as estruturas que permeiam o movimento da dialética na Fenomenologia do Espírito. Neste sentido, travou um debate com duas grandes recepções desta obra de Hegel: uma psicológica, referente aos trabalhos de Kojéve e outra sociológica, concernente ao trabalho de Marx. Labarrière enfrenta tanto o determinismo marcado pela leitura do fim da história feita por Kojéve, como o ateísmo que marca a leitura de Marx. Ambas as leituras não enxergam a dinamicidade do movimento dialético que se depreende da Fenomenologia do Espírito.

Labarrière abre portas para se pensar a dialeticidade, contribuindo para a leitura de seu próprio tempo e do nosso. Seu trabalho vai para além de Hegel. O filósofo francês foi capaz de fazer do pensamento hegeliano, uma ferramenta para se repensar inúmeras questões ligadas principalmente aos impasses sociais e políticos, advindos de leituras totalitárias.

Não há como esquecer ainda a grande contribuição de Labarrière no campo da mística cristã, principalmente com relação aos seus trabalhos devotados ao Mestre Eckhart. Em Labarrière temos a versão francesa do grande 
homem da síntese. A síntese entre o filósofo e o místico, entre aquele que une o absoluto do pensamento ao elemento contingencial da história, entre o meticuloso e duro intelectual ao claro e bem articulado comunicador do pensamento. Em Labarrière, portanto, temos a grandeza do místico e do filósofo que ousou penetrar os labirintos de um de entre os mais obscuros pensamentos filosóficos, tornando-o mais claro e compreensível, fazendo do mesmo uma ferramenta de crítica para o esclarecimento de seu e de nosso tempo.

\section{Referências Bibliográficas}

COSTA, André Oliveira; BAVARESCO, Agemir. Movimento lógico da figura hegeliana do senhor e do servo. In: Trans/Form/Ação, Marília, v. 36, n. 1, p. 37-60, Jan./Abril, 2013, p. 37-60.

LABARRIÈRE, Pierre-Jean. Structures et mouvement dialectique dans La Phénoménologie de l'esprit de Hegel. Paris: Aubier, 1968.

. Science de la logique. L'Être. Traduction, presentation, notes par P.-J. Labarrière et Gwendoline Jarczyk, Paris: Aubier, 1972.

. Science de la logique. La doctrine de l'essence. Traduction, presentation, notes par P.-J. Labarrière et Gwendoline Jarczyk, Paris: Aubier, 1976.

Dieu aujourd'hui. Cheminement rationnel, décision de liberté. Paris: Desclée, 1977

Introduction à une lecture de La Phénoménologie de l'esprit de Hegel. Paris: Aubier, 1979.

. Science de la logique. La logique subjective ou doctrine du concept. Tradution, presentation, notes par P.-J. Labarrière et Gwendoline Jarczyk, Paris: Aubier, 1981.

. Hegel, 150 ans près. In: Archives de Philosophie. Paris, 44: 1981, p. 177-188.

. Le discours de l'altérité. Une logique de l'expérience. Paris: Presses Universitaires de France, 1983.

Odes à la nuit. Paris: Éd. Saint-Germain-des-Prés, 1984.

. L'Utopie Logique. Paris: L'Harmattan, 1992.

Unité pluriel - Louange. Paris : Aubier, 1992

Poiétiques. Quand l'utopie se fait histoire. Paris: Presses Universitaires de France, 1998.

Cerf, 1999

Croire et comprendre. Approche phylosophique de l'expérience chrétienne. Pars:

Fenomenologia do Espírito uma introdução à 'modernidade'. Entrevista realizada pela Revista do Instituto Humanitas (IHU), São Leopoldo, 30 de abril de 2007, Edição 217, p. 20-27 
. Phénoménologie de l'esprit, Hegel. Collection Philo-oeuvres Paris: Ellipses, 2014.

. JARCZYK, Gwendoline. Maître Eckhart ou I'empreinte du désert. Paris: Albin Michel, 1995.

MAGALHÃES, Theresa Calvet de. O reconhecimento em Hegel: leituras de Labarriére. In: Revista do Instituto de Hermenêtica Jurídica, n. 7, Belo Horizonte, setembro de 2009, p. 311-344.

MAGALHÃES, Theresa Calvet. Imputabilidade, responsabilidade, reconhecimento: uma releitura do percurso realizado em soi-même comme un autre. In: Sapere Aude - Belo Horizonte, v. 4 - n. 8, - 2ºm. 2013, p. 56-68.

NICOLAU, Marcos Fábio Alexandre. Método e ato filosófico em Hegel. In: Revista Dialectus, ano 01, n. 02 janeiro-junho 2013, p. 1-13.

Endereço do Adilson Feiler:

Rua Padre Aloysio Sehnem, 186 - Cristo Rei

93022-630 São Leopoldo - RS

e-mail: feilersj@yahoo.com.br

E-mail do Agemir Bavaresco:

abavaresco@pucrs.br 